\title{
La financiación de las ceremonias públicas en el noroeste de España durante el siglo XVIII
}

\author{
RoBerto J. López *
}

\begin{abstract}
El interés que han ido concitando en las dos últimas décadas el reflejo de la política en la vida cotidiana, la imagen y la repercusión de su uso en la formación y utilización de la opinión pública, y el empleo político del tiempo libre de los ciudadanos para captar su asentimiento a una determinada opción, también se ha trasladado a la investigación histórica y en concreto a la relativa a la Edad Moderna '. En este contexto general, se comprende la atención que se está concediendo al estudio del arte en las cortes reales ${ }^{2}$, y la oportunidad de estudiar algunas ceremonias públicas como las proclamaciones reales, las entradas solemnes, los bautizos y matrimonios de los miembros de la realeza, las funeraciones regias, y las rogativas y acciones de gracias con ocasión de sucesos políticos y militares. Tales acontecimientos constituyen para los historiadores un medio apreciable para conocer cómo se configuraban las relaciones de poder y su imagen en la Edad Moderna, además de estudiar un componente importante de la cotidianeidad como es el espacio y el tiempo de la fiesta.
\end{abstract}

La bibliografía disponible sobre estas ceremonias públicas es abundante en Francia, Inglaterra, Italia, Portugal y también en España. A nues-

* Universidad de Santiago de Compostela.

- Brusantin, M., Historia de las imágenes. Madrid 1992; Freedberg, D., El poder de las imágenes. Estudios sobre la historia y teoría de la respuesta. Madrid 1992; SAMuel, R., «La lectura de los signos», Historia Contemporánea, 7 (1992), págs. 51-74.

2 Por ejemplo, Brown, J. y ElLIOTT, J. H., Un palacio para el rey. Madrid 1985; Cela Esteban, M. E., Elementos simbólicos en el arte castellano de los Reyes Católicos. Madrid 1991; CHECA, F., Felipe II, mecenas de las artes. Madrid 1992; Orso, S. N., Philipe IV and the Decoration of the Alcázar of Madrid. Pricenton 1986; Trevor-Roper, H., Princes and Artists. Patronage and Ideology at four Habsbourgs Courts, 1517-1633. Londres 1991. 
tro juicio, sin embargo, las virtualidades de esta abundancia quedan amortiguadas por la orientación a veces excesivamente descriptiva de sus contenidos, y por el relativamente frecuente aislamiento entre los análisis de los contenidos formales y artísticos de las celebraciones y ceremonias públicas y los relativos a sus aspectos sociales y políticos ${ }^{3}$. En general, predomina en esta bibliografía el estudio de los aspectos artísticos: el análisis formal y estilístico de las arquitecturas efímeras, la descripción y explicación de sus emblemas y jeroglíficos, el estudio de los cortejos, las representaciones teatrales y las escenificaciones festivas. Se echa en falta, salvo algunas excepciones, el intento de unificar todo el cúmulo de información disponible y de relacionarlo con otros hechos del momento, es decir, de situar a las celebraciones públicas en su contexto social, político y cultural. Por contra, en no pocos casos se sucumbe a la tentación de rodear las celebraciones de la Edad Moderna de un cierto halo misterioso que las aleja de su realidad histórica, al repetir casi mecánicamente lugares comunes que a veces se aceptan sin demostrar, o al menos sin comparar con otros períodos históricos de manera que se pueda aceptar su pretendida especificidad.

La atención preferente a los aspectos externos y el mantenimiento de esos lugares comunes han hecho que permanezcan en la penumbra por poco conocidos determinados aspectos de las ceremonias públicas, como es el caso de su financiación. Un conjunto de problemas derivados de la documentación disponible y del modo en que las cuestiones económicas se trataban en la Edad Moderna también contribuye a que el interés específico por este aspecto haya quedado amortiguado. Nuestro propósito es determinar cuáles son esos problemas, las limitaciones que imponen y los resultados a los que permiten llegar. Tomamos para ello un marco geográfico y temporal concreto, el de Galicia en el siglo XVIII, un ámbito específico dentro de la España moderna en el que se pueden estudiar los recursos empleados para costear las ceremonias públicas, sus efectos sobre las economías urbanas, y las modificaciones que introdujo la política reformista de Carlos III a partir de 1760 .

\section{NÚMERO Y DURACIÓN DE LAS CEREMONIAS PÚBLICAS}

Para poder situar en su contexto la financiación de las ceremonias públicas y su repercusión en las economías urbanas de la Edad Moderna,

3 Se llama la atención sobre esta excesiva compartimentación en Strong, R., Arte y poder. Fiestas del Renacimiento. Madrid 1988, pág. 172. 
resulta necesario establecer de manera aproximada cuántas se celebraron y cuál fue su duración también aproximada. Algunas referencias se pueden extraer de la documentación concerniente a Santiago de Compostela, la ciudad cabeza del Antiguo Reino de Galicia. Pensamos que dadas las características de estas ceremonias, así como su vinculación con las autoridades centrales, tanto su variedad como frecuencia debieron ser muy similares en las demás ciudades gallegas, por lo que el estudio de lo ocurrido en Santiago podría extenderse en sus líneas generales a las otras capitales de Galicia (La Coruña, Betanzos, Mondoñedo, Lugo, Orense y Tuy). Según la documentación consultada, se celebraron entre los años 1700 y 1833 en Santiago, 252 ceremonias públicas, en las que van comprendidas varias proclamaciones reales, la celebración de acontecimientos de la familia regia, los festejos por victorias militares y por éxitos políticos, entradas públicas y otras celebraciones - las menos- más vinculadas a la vida compostelana ${ }^{4}$. La distribución cronológica resulta desigual, con una concentración mayor en los reinados más conflictivos de Felipe $V$ (Guerra de Sucesión) y de Fernando VII (enfrentamientos entre absolutistas y liberales), lo que pone de manifiesto algo que no por sabido debe olvidarse, como es la finalidad que se busca con estas ceremonias, y que genéricamente puede establecerse en la utilización del tiempo libre de los vecinos de las ciudades y de sus deseos de diversión para difundir una imagen favorable del poder o recabar su apoyo, según sea el caso ${ }^{5}$.

La duración de las celebraciones variaba según los motivos de su convocatoria y también según las posibilidades de tiempo, de medios humanos y de dinero ${ }^{6}$. Algunas duran sólo un día. Es el caso de ciertas

\footnotetext{
4 El período cronológico abarca desde la llegada al trono de España del primer Borbón, Felipe V, hasta el final del reinado de Fernando VII. Para establecer la cantidad indicada, se revisaron todos los acuerdos municipales ( 314 tomos de actas), y los registros de la fábrica catedralicia (legajos 535 a 545) entre ambos años; y las actas de los claustros universitarios entre 1696 y 1809 (libros 126 a 137). Se emplisan las siguientes abreviaturas: ACS (Archivo de la Catedral de Santiago), AHUS (Archivo Histórico de la Universidad de Santiago), AMC (Archivo Municipal de La Coruña), AMS (Archivo Municipal de Santiago), y ARG (Archivo del Reino de Galicia).

5 Se desarrollan estas ideas en LóPEZ, R. J., «Celebraciones públicas en Galicia durante el siglo xvII!», Obradoiro de Historia Moderna, 1 (1992), págs. 186-187; en este trabajo se señalan únicamente 198 ceremonias porque la información que se manejó era menos abundante que la que ahora usamos.

6 Al hablar de duración nos referimos a ella en un sentido estricto: únicamente a los días en los que se desarrollan las funciones programadas. En un sentido amplio, las celebraciones pueden considerarse de una duración mayor si se tienen en cuenta los días en los que se dan a conocer mediante bandos, o los fuegos y ceremonias religiosas que se celebran de modo inmediato cuando llega una noticia, etc. Todo esto haría que el espacio temporal ocupado por cada celebración se pueda tomar con unas dimensiones mayores que las que aquí señalamos.
} 
celebraciones como las entradas públicas de los nuevos arzobispos y de algunas acciones de gracias relacionadas con victorias militares ${ }^{7}$. Otras ceremonias públicas prolongan sus actos durante dos o tres jornadas. Los funerales regios suelen durar al menos dos, una para las vísperas y la siguiente para el funeral propiamente dicho; también duraron más de un día algunas acciones de gracias ${ }^{8}$. En ciertas ocasiones se sobrepasa la semana; esto sucedió, por ejemplo, en la celebración orensana del nacimiento de Luis I, que comenzó el 30 de agosto de 1707 y terminó el 11 de septiembre ${ }^{9}$, y en las rogativas que ordenó hacer Felipe $V$ por el éxito de la expedición del rey Jacobo a Escocia en 1708, que debían durar nueve días ${ }^{10}$.

Si se considera una duración media por cada festejo de tres días, resulta que de los algo más de ciento treinta años que se estudian, algo más de dos estuvieron íntegramente dedicados a las ceremonias públicas en Santiago de Compostela. Como probablemente el número de éstas fue superior a las 252 que contabilizamos, y habida cuenta de que a los días de la celebración propiamente dicha habrá que añadirle los destinados a su preparación y anuncio, esos dos años se pueden subir al menos a tres; basta con añadir un día más a la media anteriormente citada. Los tres años pueden incrementarse todavía más, probablemente hasta cinco, si se considera que las 252 ceremonias que contamos son las extraordinarias, y que por tanto a éstas hay que añadir las que se celebran anualmente de manera fija. Este sencillo cálculo no pretende en absoluto dar resultados precisos, sino mostrar que las ceremonias públicas tuvieron una frecuencia relativamente alta, y que por tanto absorbían una importante cantidad de recursos, aunque tal importancia debe medirse no tanto en términos absolutos como en relación a las economías de las instituciones y particulares que participaban en ellas. Estudiar cuánto y cómo se gastaba en las ceremonias públicas se convierte así en una cuestión que no es simple erudición, sino un medio para conocer diversos aspectos de la vida urbana y política del Antiguo Régimen.

\footnotetext{
7 Sirva de ejemplo la acción de gracias por la victoria de Felipe $V$ en Valencia; en AMS, Consistorios de 1707, $1 .{ }^{\text {er }}$ semestre, fs. 315 vto -352 .

8 Tres días dura la celebración de la victoria de Felipe $V$ en Sicilia; en AMS, Consistorios de 1719 , enero-septiembre, fs. 342 y vto.

- Butrón, J., El clarín de la Fama y cithara de Apolo, Imprenta de Antonio de Aldemunde. Santiago 1708. Sobre esta obra, LóPEZ, R. J., «Una relación festiva del siglo XVIII; la celebración en Orense del nacimiento del Príncipe Luis según el Padre Butrón», en Jornadas Dieciochistas. Homenaje al Prof. Caso González. Oviedo 1992, en prensa.

${ }_{10}$ AMS, Consistorios de 1708,1 er $^{\text {er }}$ semestre, f. 228 . Se hicieron del 11 al 20 de abril de 1708 en la colegiata de San Agustín.
} 


\section{LA INFORMACIÓN SOBRE LOS GASTOS}

El gasto que generaban las celebraciones era tan variable como su duración, dependiendo no sólo de ésta sino del tipo de función y del estado de las arcas municipales y de otras instituciones urbanas. Este último extremo no resulta sin embargo tan determinante como pudiera imaginarse. El exceso en el gasto del que más abajo se verán algunos datos, era moneda corriente dentro y fuera de Galicia, y estuvo en el origen de algunas medidas de gobierno y de algunas protestas ${ }^{11}$.

El cálculo de los gastos que una ceremonia pública suponía para una ciudad es muy difícil de evaluar. Se debe tener en cuenta que en cada ocasión interviene no sólo el municipio sino otras instituciones, de manera que el costo general de las ceremonias no se averigua revisando únicamente las contabilidades municipales; hay que revisar también las catedralicias, las gremiales, y si es el caso las de la Universidad, Inquisición, Real Audiencia, monasterios y conventos. Además, es necesario tener presente el gasto que recae sobre los particulares, bien sea de modo voluntario, bien sea de modo forzoso. Los vecinos se veían obligados a poner luminarias, limpiar y adecentar las calles para contribuir así al buen fin de los festejos; una obligación que se reforzaba en ocasiones con pesadas multas ${ }^{12}$. La participación de algunos vecinos cualificados fue algunas veces más allá de la simplemente impuesta, tal vez — seguroconscientes del aval que constituía para su prestigio social y político la aportación a las ceremonias. En algunos casos, ésta consistía en el adorno especial de sus casas o incluso navíos ${ }^{13}$, mientras que en otros en la

\footnotetext{
11 Se señalan algunas de estas medidas y protestas, entre otros lugares, en DURÁN MONTERo, M. A., "La entrada en Lima del Virrey Don García Hurtado de Mendoza", Laboratorio de Artes, 3 (1990), págs. 58-59. Deleito Piñuela reproduce algunos versos críticos del siglo XVII (El rey se divierte. Madrid 1988, págs. 164 y 239). También Jovellanos expuso su opinión contraria ante gastos tan fastuosos como pasajeros (FERNÁNDEZ DELGADO, J., "Política y memoria del buen gusto. Las fiestas reales de 1789», Goya, 181-182 [1984], pág. 63).

12 Para la celebración del nacimiento del príncipe Luis, futuro Luis I, el Ayuntamiento de Santiago ordena a sus vecinos que coloquen luminarias en sus ventanas, bajo multa de diez ducados (AMS, Consistorios de 1707, $2 .^{\circ}$ semestre, f. 712). Unas órdenes similares se cursaron en La Coruña en 1836 con motivo de la publicación de la Constitución (AMC, C-963, «Expediente formado en virtud del Real Decreto del 13 de agosto [de 1836] por el cual se manda la publicación de la Constitución política de 1812 en toda la Nación»).

${ }^{13}$ En la proclamación de Fernando VII en La Coruña el regidor decano de la Audiencia adornó de manera especial la fachada de su casa; Don Juan Bautista de Larragoiti su fragata, atracada en la bahía coruñesa (Breve resumen de las fiestas que celebró... La Coruña en la augusta proclamación del sr. rey D. Fernando VII, Oficina del Exacto Diario. La Coruña 1815, págs. 24-25).
} 
financiación de iniciativas menos llamativas pero igualmente interesantes como la edición de sermones y relaciones festivas ${ }^{14}$.

Así las cosas, se comprende que un estudio de estas características sea difícil de realizar, no tanto por la complejidad documental como por la ausencia de información. Dejando a un lado las pérdidas de libros de cuentas, los que se conservan no suelen informar de todo; al llevar cada institución contabilidades separadas según conceptos diversos, se hace difícil reconstruir los movimientos de las arcas municipales y catedralicias, detectar los fraudes y ocultaciones, y por consiguiente evaluar adecuadamente el peso que sobre la economía de las instituciones tuvieron las ceremonias públicas ${ }^{15}$. Por si esto no fuera suficiente, determinadas partidas gastadas en la agilización de los trámites para organizar las celebraciones o para solucionar conflictos y pleitos, no se hacen constar en las cuentas por tratarse de gastos secretos, y cuando aparecen lo hacen bajo conceptos que poco o nada tienen que ver con los realmente efectuados ${ }^{16}$. Hay que contentarse con datos parciales y suponer que si bien no reflejan toda la realidad, al menos ponen de manifiesto su tónica general.

Para mostrar algunas de estas cuestiones económicas relacionadas con las ceremonias públicas, emplearemos los datos provenientes de los libros municipales y catedralicios de Santiago, por ser los que ofrecen una información económica mayor y más continuada. No debe olvidarse, como se acaba de señalar un poco más arriba, que hay otras instituciones

14 Por ejemplo, la Oración fúnebre en las solemnes exequias que el llmo. Señor Arzobispo, Dean y Cabildo de la... Iglesia del Señor Santiago... celebró el 17 de diciembre de 1760 a la... memoria de... Doña María Amalia de Saxonia, Reyna de las España, Imprenta de Pedro Fraiz, s.l. (Santiago), s.a. (1761), que predicó D. Simón Díaz de Rávago, penitenciario de la catedral; la publicó, según consta en la portada, «un apasionado del orador» cuyo nombre se oculta. Otro "apasionado" y anónimo seguidor de fray Joaquín Andrade, predicador del convento de San Francisco de Betanzos, publicó el Sermón que en acción de gracias por el feliz nacimiento de los señores infantes gemelos Carlos i Felipe i ventajoso ajuste de paz, dijo a la... ciudad de Betanzos..., Imprenta de Ignacio Aguayo, s.l. (Santiago), 1784.

15 El efecto sobre las economías particulares puede considerarse, salvo excepciones muy contadas, como imposible de abordar.

${ }_{16}$ A propósito de un pleito entre la ciudad de Santiago y el Hospital Real por el tablado que se levantó en la plaza del Hospital (Obradoiro) en 1745 para la corrida de toros del día de Santiago, se gastaron 2.790 reales en concepto de gastos secretos; el agente de la ciudad ante la Cámara de Castilla señaló en carta adjunta a la relación de agasajos otorgados, que «los gastos extraordinarios secretos que van separados, no pueden sonar en quenta alguna y es preciso subsanarlos bautizándolos aunque sea con el nombre de gratificación o como lo discurran vuestras mercedes mejor" (citado en Pérez CostantI, P., Notas viejas galicianas, t. II. Vigo 1926, pág. 280). La relación de los gastos ordinarios y extraordinarios efectuados en esa ocasión, en AMS, Consistorios de $1745,4{ }^{\circ}$ trimestre, fs. 278-283. 
que gastan y a veces bastante en proporción a sus ingresos y posibilidades. A título de ejemplo, se pueden citar los cerca de 15.000 reales que el Colegio de Fonseca gastó en la celebración del nombramiento de Don Cayetano Gil como arzobispo de Santiago en 1745, y los 900 reales que al año siguiente destinó para los fuegos con los que se festejó el ascenso de Don Antonio Varela a regente de la Audiencia de Canarias ${ }^{17}$. Los gremios también destinaron una parte de sus fondos a la financiación de las ceremonias públicas; su participación en los costos no estuvo exenta, sin embargo, de ciertos conflictos y problemas que ponen de manifiesto algunas dificultades de la actividad gremial y, claro está, la carga económica que en determinadas circunstancias les causaban los festejos públicos ${ }^{18}$. A pesar de todo, se puede afirmar que los gremios participaron gustosamente en los actos, procurando alcanzar el mayor lucimiento posible y tratando de superar en lo posible la actuación de otras corporaciones ${ }^{19}$; en algunos casos la ostentación puede calificarse de notoria ${ }^{20}$.

\section{LOS GASTOS MUNICIPALES}

Los gastos más elevados eran, como cabría esperar, los que recaían sobre las arcas municipales, y especialmente cuando se trataba de actos relacionados con la Monarquía y la Constitución; veamos algunos casos.

17 AHUS, Fondo Universitario, Sección Histórica, libro 133, fs. 31 vto y 96 vto, respectivamente.

18 Un ejemplo de las primeras lo constituye la condición puesta por el gremio de plateros compostelanos para participar en los actos de proclamación de Carlos III, por la que exigían que el Ayuntamiento exigiese a los plateros no agremiados que contribuyesen en los costes lo mismo que los agremiados (AMS, Consistorios de 1759, septiembre-diciembre, fs. 69 y vto.). Con respecto a las dificultades estrictamente económicas, vale de ejemplo la protesta de los gremios de Santiago por el excesivo coste que suponía la celebración de la toma de Orán (AMS, Consistorios de 1732, julio-diciembre, f. 560;.

${ }_{19}$ El gremio de calceteros y cordoneros de Santiago gastó 200 reales en la función de proclamación de Carlos III (AHUS, Bienes Nacionales, leg. 1063, f. 65). De la rivalidad entre los gremios lucenses quedó constancia en la Relación de las festivas demostraciones con que la... ciudad de Lugo... expresó sus júbilos en la aclamación... de... el señor Don Fernando VI. Santiago, Imprenta de Buenaventura Aguayo, 1746, pág. 3.

20 Los comerciantes compostelanos confeccionaron, costearon y sacaron a la calle un carro triunfal en los festejos por el nacimiento en 1783 de los infantes Carlos y Felipe, nietos de Carlos III; las alegorías que portaban constituían no sólo una exaltación del monarca y de la monarquía, sino del cuerpo de comerciantes, de su lealtad e importancia en la vida de la ciudad (AMS, Consistorios de 1783, noviembre-diciembre, fs. 350 vto-352). Unos años más tarde, en 1814, esta corporación participó activamente en los festejos de la restauración absolutista de Fernando VII; costeó el vestido de 140 pobres, que desfilaron por toda la ciudad, y la comida que se les dio (López Ferreiro, A., Historia de la S.A.M. Iglesia de Santiago de Compostela, t. Xl. Santiago 1909, apéndice n. XXVII). 
En la acción de gracias por el embarazo de la reina María Luisa de Saboya, el Ayuntamiento de Santiago gastó cerca de 3.150 reales, y en la celebración del nacimiento del príncipe Luis más de 20.000 reales $^{21}$; el nacimiento de los infantes Carlos y Felipe en 1783 supuso un gasto para el municipio de casi 6.000 reales ${ }^{22}$; la proclamación de Carlos IV casi alcanzó los 176.400 reales $^{23}$; y la proclamación de la Constitución de 1812 unos 30.000 reales ${ }^{24}$. Algún hecho excepcional también provocó un gasto relativamente alto, como la canonización de San Pío V en 1713, para cuya celebración el municipio dedicó aproximadamente unos 4.800 reales ${ }^{25}$. En otras celebraciones como las rogativas -incluso las relacionadas con la familia real-y acciones de gracias por hechos políticos o militares, los gastos no son tan altos; pocas veces superan los 1.000 reales, y en casos excepcionales están por debajo del centenar de reales ${ }^{26}$.

De todos modos estos gastos son únicamente indicativos, pues no se corresponden realmente con el total gastado que suele ser mayor; varias circunstancias permiten afirmarlo. En las actas consistoriales y en los libros de cuentas del Ayuntamiento de Santiago no se consignan todas las celebraciones ni todos los conceptos ${ }^{27}$, y cuando así se hace es de manera dispersa, según se van librando, de modo que es difícil llegar a reunirlos al completo ${ }^{28}$. Por otra parte, como tales gastos suelen adelantarlos los comisarios de la celebración $u$ otra persona si no hay liquidez en las arcas consistoriales, puede transcurrir bastante tiempo entre la celebración y el momento en que se hacen efectivas esas cantidades ${ }^{29}$. A

21 AMS, Consistorios de 1707, 1. ${ }^{\text {er }}$ semestre, f. 246 vto; y Consistorios de 1708, $1 .{ }^{\text {er }}$ semestre, fs. 2-15.

22 AMS, Consistorios de 1783, mayo-octubre, fs. 317 y vto.

23 Concretamente 176.385 reales y 27 maravedís (AMS, Juntas de Propios y Arbitrios, 1792 $1794, \mathrm{f} .105)$. Un poco más abajo se comenta por extenso este gasto.

24 AMS, Consistorios de 1812, agosto-diciembre, fs. 422 y vto.

25 AMS, Consistorios de 1713, enero-abril, fs. 490 y vto.

26 La ciudad gastó 501 reales en la celebración de la victoria real en Campo de la Gudiña (Badajoz) en 1709 (AMS, Consistorios de 1709, mayo-octubre, f. 476); en octubre de 1719 se gastan 89 reales en una rogativa por el buen fin del ejército en Ceuta (AMS, Cuentas de Propios y Arbitrios, $1709-1754$, fs. 45 y vto)

27 En el año 1814 se celebró en Santiago entre otros hechos la restauración absolutista de Fernando VII, el restablecimiento de la Inquisición y el regreso del arzobispo Múzquiz. A pesar de la participación municipal en tales eventos, las cuentas de propios y arbitrios de ese año y de los siguientes no recogen ningún gasto extraordinario por esos conceptos; únicamente 1.259 reales de una rogativa pública los días 4 y 5 de junio "por el feliz acierto de nuestro Soberano" (AMS, Juntas de Propios y Arbitrios, 1810-i815, f. 411 vto).

${ }_{28}$ El 2 de septiembre de 1794 se aprobó una libranza de 2.873 reales para unas rogativas que se celebraron por el éxito de las armas españolas, «sin incluir — se dice en la documentación- lo que deben haber las comunidades por su asistencia» (AMS, Juntas de Propios y Arbitrios, 1792-1794, f. 451).

29 En 1801 el Ayuntamiento compostelano pagó los 112 reales que debía desde 1798 al 
estas irregularidades se deben añadir otras que son el resultado de la inclusión de gastos producidos por las celebraciones entre los ordinarios del municipio. Esto sucede, por ejemplo, con los derivados de los pleitos que se suscitan por discusiones protocolarias y por la organización de las celebraciones, y que unas veces se incluyen específicamente entre los gastos de tales eventos, pero otras entre las asignaciones anuales de los procuradores de la ciudad ante la Real Audiencia de Galicia y la Corte. Tampoco es frecuente que se incluyan entre los gastos los correspondientes a la publicación de relaciones y de sermones pronunciados en la ocasión $^{30}$.

En cualquier caso, con independencia de los valores particulares y de las limitaciones documentales de cada caso, lo que sí parece quedar claro es una cierta jerarquía económica de las ceremonias, según se desprende de las cantidades indicadas al inicio del apartado.

\section{LOS GASTOS DEL CABILDO CATEDRALICIO}

La información procedente de la documentación catedralicia es más abundante que la municipal, aunque está más dispersa entre diferentes libros y recibos, lo que dificulta la reconstrucción de los gastos. Una parte de éstos además, sobre todo cuando conciernen a determinados artesanos (pintores, carpinteros, orfebres o tejedores) y proveedores (cereros y coheteros), se inciuyen en los jornales y pagos generales acordados con ellos, por lo que resulta poco menos que imposible determinar qué parte de esas cantidades corresponden a gastos ordinarios y cuál a las ceremonias públicas. En cualquier caso se puede decir que el nivel de gasto es alto, aunque no tanto como el municipal, y con algunas partidas específicas $^{31}$.

portero por haberlos suplido para los gastos de iluminación de las casas consistoriales en la entrada del nuevo arzobispo (AMS, Juntas de Propios y Arbitrios, 1800-1803, f. 306); es uno de los muchos ejemplos que se pueden proponer.

30 Únicamente encontramos una referencia a tal gasto; se trata de la edición del relato de la proclamación de Carlos III, cuyos 600 ejemplares costaron 1.200 reales (AMS, Consistorios de 1760, enero-abril, f. 253 vto, y mayo-septiembre, fs. 144-145). La relación a la que se refieren estos acuerdos tal vez sea la de Cernadas de CASTro y UlloA, D. A., Carta-quenta... de las fes tivas gozosas demostraciones con que la... cludad de Santiago... celebró en solemne aclamación de... Carlos III. Imprenta de Antonio Fraiz, Santiago, s.a.

31 Hay, de todos modos, algunas partidas excepcionalmente altas, como los 13.000 reales que se gastaron en la recepción a Jacobo lll en 1719 (ACS, leg. 536, libro de fábrica, 17161756 , f. 25 vto), y los cerca de 138.000 reales gastados en la celebración del nombramiento de Don Pedro de Acuña como Secretario de Gracia y Justicia (ACS, leg. 996-C, Fábrica. Comprobantes de cuentas de 1789-1793). 
Una de estas partidas es la correspondiente a los túmulos de los funerales reales. Se aprecia en este caso el problema que se acaba de indicar arriba, pues no siempre se hacen constar todos los gastos que supuso el túmulo, tanto en materiales como en mano de obra, lo que hace sospechar que en tales casos se haya pagado con los jornales y con los contratos generales de abastecimiento. Algunos ejemplos ayudarán a ver el gasto que originaron estos túmulos, aunque sea de manera parcial. Así, el que se levantó por la reina María Luisa de Saboya en 1714 supuso un gasto sólo entre el pago de los pintores y de las pinturas de 1.130 reales ${ }^{32}$. En el de Luis I se gastaron 2.405 reales en los sueldos de los pintores, además de otros 584 reales en la bayeta negra que se usó para cubrirlo ${ }^{33}$. En el túmulo de Mariana de Neoburgo, viuda de Carlos II, se gastaron 246 reales para pintarlo; teniendo en cuenta la cantidad, lo más probable es que tal pintura fuera simplemente un retoque de la anterior ${ }^{34}$. Juan Antonio de Bouzas recibió 600 reales en 1746 por pintar el túmulo de Felipe V; no tenemos más noticias sobre gastos de esta arquitectura efímera ${ }^{35}$. Las cuentas del túmulo levantado para las exequias de Carlos III son más extensas: 249 reales por las maderas que se compraron para el túmulo, 254 reales a los oficiales que trabajaron cuatro noches para armarlo en la catedral, 834 reales de bayeta, y 2.150 reales al pintor Juan Bernardo del Río ${ }^{36}$. Menos fue lo que se gastó en armar y pintar los túmulos que en 1819 se hicieron por la reina María Luisa de Braganza, y por Carlos IV y María Luisa de Borbón; en total, unos 1.250 reales ${ }^{37}$. Una serie de gastos más pequeños que los anteriores a pesar de tratarse de situaciones similares, obliga a pensar que en esas ocasiones no se construyó un nuevo túmulo, sino que se reutilizó uno anterior a los materiales almacenados de los precedentes. Esto es lo que sucede con los catafalcos del Delfín, padre de Felipe V, en 1711, de la viuda de Luis I en 1742, y el de Amalia de Sajonia en 1761, por citar tan sólo tres ejemplos ${ }^{38}$.

32 ACS, leg. 970-C, Fábrica. Comprobantes de cuentas, 1714-1716, doc. suelto.

33 ACS, leg. 536, libro de fábrica, 1716-1756, f. 115.

34 Ibidem, fs. 212 vto-213.

35 Ibidem, f. 363.

36 ACS, leg. 538, libro de fábrica, 1782-1789, fs. 142 vto-143 vto.

37 ACS, leg. 543, libro de fábrica, 1814-1821, s.f. (data de 1819).

38 Del primero únicamente se seřala un gasto de 64 reales a favor de Francisco Sánchez por "haver retocado de pintura el túmulo", cantidad que incluye además la pintura del hacha de la candelaria y palma del Domingo de Ramos para el arzobispo (ACS, leg. 535, libro de fábrica, $1686-1716$, f. 380 vto). Del túmulo de 1742 la única noticia que se encuentra son los 75 reales pagados a Juan Antonio de Bouzas «por obra para el túmulo» (ACS, leg. 536, libro de fábrica, $1716-1756$, f. 275 vto). El tercer caso es más peculiar porque en el libro de fábrica sólo encontramos un gasto, los 225 que costó la arroba de chocolate que se regaló al que compuso las letras del túmulo; pero sobre montaje y pintura del mismo no aparece nada, lo 
Otro de los gastos específicos que estas ceremonias suponen para la mesa capitular son los «interpresentes» que deben pagarse a los canónigos ${ }^{39}$. Como muestra, cabe señalar los 2.200 reales que a finales de febrero de 1819 libró el canónigo contador de horas del coro sobre el mayordomo por acuerdo del cabildo, para que se repartiesen entre los canónigos que asistieron a las exequias de Isabel de Braganza el 18 de febrero de ese año ${ }^{40}$.

\section{CRÉDITOS Y ENDEUDAMIENTOS}

Algunas decisiones adoptadas por los ayuntamientos parecen indicar que el prestigio que reportaban las celebraciones y su funcionalidad social y política eran un poderoso aliciente para su organización, de modo que la reacción habitual ante la posible falta de recursos no era la de suspender los actos, sino buscar los medios económicos a pesar de las dificultades que esto pudiera generar ${ }^{41}$. Por eso no resulta sorprendente sino que hasta se puede considerar normal que menudeen las reclamaciones de maestros de carpintería, pintores y otros artesanos por el impago de su trabajo y que, con menor frecuencia, se adopten medidas para disminuir determinados gastos. El 7 de junio de 1747, por ejemplo, se propuso y aprobó en el consistorio de Santiago una reducción en el gasto de la cera que se utilizaba en las funciones reales y otras a las que debía asistir la ciudad; según el acuerdo adoptado, desde ese momento cada miembro de la ciudad recibiría únicamente cera «por un solo empleo", no como hasta entonces, que se les entregaban las hachas correspondientes a cada cargo desempeñado ${ }^{42}$.

que hace pensar que probablemente se usase uno anterior (ACS, leg. 537, libro de fábrica, 1757-1781, f. 90 vto).

39 Se trata de la participación de los canónigos residentes en los derechos de culto y clero.

40 ACS, leg. 43, Libro de gastos extraordinarios de la mesa capitular, 1788-1827, s.f.

${ }^{41}$ Sólo encontramos un caso de posible suspensión de una ceremonia por falta de dinero; se trata de la proclamación de Fernando VI en La Coruña. Las actas municipales de 1746 no recogen su celebración, pero sí la declaración de su carencia económica y su petición de ayuda al propio monarca (Martínez BARBEITO, C., «Las reales proclamaciones en La Coruña durante el siglo XVIII", Revista del Instituto José Cornide de Estudios Coruñeses, 1 (1965), págs. 43-44).

${ }_{42}$ "Y oído por los más señores acordaron que de aquí adelante en quanto se ofresca no se den achas ni propinas dobles a los señores alcaldes siendo señores capitulares, ni a los secretarios de Ayuntamiento si tubieren los empleos de señores alcaldes o procurador xeneral ni a otro alguno más, dé solamente reputados por un solo empleo, y esto se tenga presente en quanto se ofresca y anote en los oficios, y a los señores capitulares o procuradores xenerales a quienes se hagan encargos en los casos que se ofrescan, se haga presente este acta para su cumplimiento» (AMS, Consistorios de 1747, 2. ${ }^{\circ}$ trimestre, fs. 193 y vto). En la misma sesión se decidió no volver a dar cera a la comunidad de San Francisco en la función anual de la Vera 
Los problemas alcanzan mayores dimensiones en algunos casos, en los que se tiene la impresión de que se dispone por encima de las posibilidades reales. Así, la deuda con los cereros y coheteros en las fiestas por el nacimiento de Luis I se hubo de cubrir con los fondos de los arbitrios

«Por no aver otros y aver mandado S.M. y el señor marqués de Resbourg (capital Geneal de Galicia) se hiciesen quantas demostraciones pedía semexante noticia» ${ }^{43}$.

Otro caso similar se produce en las exequias de Mariana de Neoburgo; la ciudad tuvo que aprobar un cargo especial sobre la tesorería municipal para costear los lutos de sus autoridades ${ }^{44}$. Mayor gravedad reviste la actuación de la ciudad en las exequias de Felipe $V$ y la proclamación de Fernando VI. El 24 de agosto de 1746 dirigió una petición al Marqués de la Ensenada para que cesaran algunas recaudaciones reales y así poder disponer de los 60.000 reales que se calculaba que costarían las funciones ${ }^{45}$. Cuando en marzo de 1747 se presentan las cuentas -59.819 reales y 21 maravedís ${ }^{46}$ - se advierte que la ciudad no dispone de recursos propios, que el dinero se pidió prestado y que debía solicitarse el permiso del Consejo para repartir el gasto sobre la provincia de Santiago ${ }^{47}$. El Consejo aprobó el repartimiento ${ }^{48}$; al tratar de ponerlo en práctica, surgieron controversias y dificultades que obligaron a intervenir al intendente y al traslado de las reclamaciones al Consejo para que fuera éste quien las resolviera ${ }^{49}$.

Cruz para evitar fraudes, pues «con la ocasión de dárselas (las hachas) a la comunidad, se extrahen porción de ellas" (Ibidem, f. 193 vto).

${ }^{43}$ AMS, Consistorios de 1708, 1. er semestre, f. 39. Unos años después, en 1724, el Ayuntamiento de La Coruña tuvo que recurrir a un impuesto especial para financiar la ceremonia de proclamación de Luis I al no tener fondos disponibles en su caja (MARTínez Barbeito, C., "Las reales proclamaciones..., págs. 30 ).»

44 AMS, Consistorios de 1740, mayo-octubre, fs. 281 vto-282.

${ }_{45}$ AMS, Consistorios de 1746, agosto-octubre, fs. 89 y vto.

46 De estos 4.500 reales correspondieron al coste de una máscara formada por cien parejas a caballo que figuraban las cuatro partes del mundo, y un carro triunfal «echo a todo coste» en el que iba «la música y capilla» de la catedral (AMS, Consistorios de 1747, $1^{\text {er }}$, semestre, $f$. 309vto).

${ }_{47}$ AMS, Consistorios de $1747,1^{e r}$. semestre, fs. 309-312vto y 329. "Por no tener la Ciudad caudales ni efectos, que aunque goza el corto arvitrio de quatro reales en moio de vino, recauda S. M. la mitad de su ymporte y de la ctra mitad un quatro por ciento, sin que aunque le gozase por entero llegase a alcanzar los fines a que se alla destinado como consta de las últimas quentas dadas y presentadas (...), por cuia razón y no faltar la Ciudad a celebrar funciones tan precisas en fuerza de su lealtad y de las reales órdenes que tubo para ello, solicitó sacar a empréstito dicha cantidad, la que está deviendo a acreedores, y para darle satisfacción suplica a los señores del Real y Supremo Consejo..." (f. 312vto).

48 AMS, Consistorios de 1748, $1^{\text {er }}$. semestre, fs. 366 y vto.

49 Ibidem, $2^{\circ}$ semestre, fs. 210 y ss., 228,276 y vto. 
Los problemas financieros se reproducen en la proclamación de Carlos III, sin que por eso se anulen o reduzcan las celebraciones. El 13 de septiembre el Ayuntamiento compostelano aprobó la solicitud de un préstamo de 36.000 reales con un interés del $8 \%{ }^{50}$; tres días después se modificó el acuerdo al haber recibido la oferta de un comerciante dispuesto a hacer el préstamo al $6 \%{ }^{51}$. En febrero de 1760 la ciudad recibió una carta del administrador de las Bulas de Santiago, en la que reclamaba el pago de los 36.000 reales, prestados durante 4 meses con un interés del $1 \%$; al administrador se le comunicó

«De parte de la Ciudad los deseos que le asisten de pagarle su crédito, y para ello está practicando vivas dilixencias, y que mientras no se le completa le están corriendo sus réditos y que espera desempeñarse» 52 .

Tras las reformas municipales iniciadas por Carlos III, y de manera particular con el establecimiento en 1760 de una Contaduría General de Propios y Arbitrios en el Consejo de Castilla y de las oportunas Contadurías Provinciales, la administración de estos fondos municipales quedó sometida al arbitraje de estas instituciones ${ }^{53}$. Correspondía a las Contadurías Provinciales y a los intendentes supervisar en primera instancia los gastos extraordinarios y autorizar aquellos que fuesen inferiores a 200 reales; en caso de superar esta cantidad, el permiso debía concederlo el Consejo ${ }^{54}$. Por lo general, estos gastos se aprobaron, aunque hubo alguna excepción y alguna reconvención sobre excesos cometidos. Esto sucedió, por ejemplo, con ocasión de la entrada pública del arzobispo Bocanegra en Santiago, en la que la ciudad recibió una real orden en la que se le prohibía usar los fondos de propios y arbitrios para los adornos de dicha entrada ${ }^{55}$.

Tambien discrepó el Consejo con los gastos efectuados por el municipio santiagués en la proclamación de Carlos IV; el episodio sirve, además de testimonio del intento de controlar la vida municipal desde la Corte, para conocer mediante un hecho particular una de las causas del

\footnotetext{
50 AMS, Consistorios de 1759, septiembre-diciembre, fs. 32-33.

51 Ibidem, fs. 34 y vto.

52 AMS, Consistorios de 1760, enero-abril, fs. 55 y 56vto-57. Es de suponer que se hizo efectivo el pago, pues no vuelve a tratarse el tema con posterioridad a esta fecha.

${ }_{53}$ GuILlamón, J., Las reformas de la administración local durante el reinado de Carlos III. Madrid 1980, págs. 187-198. La Contaduría General se suprimió en 1836.

${ }_{54}$ Sobre las competencias de los intendentes en el control de propios y arbitrios, Novisima Recopilación, libro VII, título XVI, ley XIII, párrafos 5-10, y leyes XVIII, XIX y XXI.

${ }_{55}$ AMS, Consistorios de 1773, septiembre-diciembre, fs. 193 y vto.
} 
endeudamiento de las haciendas concejiles y de los medios que se utilizaban para lograr fondos cuando no había disponibilidad en sus arcas. La cantidad que la ciudad empleó en la proclamación de Carlos IV ascendió, como ya se dijo, a 176.385 reales aunque ésta no era la cantidad inicialmente prevista. Según los comisarios, se necesitaban unos 140.000 reales que la ciudad no tenía en sus fondos de propios y arbitrios, por lo que se tomaron de lo que se recaudaba por los derechos de paso de mercancías sobre el río Ulla en dos puntos próximos a Santiago, las barcas del Ulla y Sarandón ${ }^{56}$. Cuando ya había transcurrido más de un año, en mayo de 1790, se envió la relación de los gastos de la proclamación al intendente para que éste le diese su aprobación ${ }^{57}$. En diciembre de ese año el intendente envió una carta a la ciudad en la que informaba que su contador de propios no admitía como correspondiente a esa cuenta los 109.043 reales destinados a los fuegos artificiales; la ciudad, que era por supuesto de la opinión contraria, decidió entonces enviar una reclamación al Consejo de Castilla ${ }^{58}$. En abril de 1791 se recibió una carta de Floridablanca en la que comunica la autorización del gasto, al tiempo que se advierte a la ciudad que en lo sucesivo debía evitar semejantes dispendios $^{59}$.

Además de estas discusiones sobre aceptación de determinados gastos, lo que importa destacar es que en realidad el monto total superó los 140.000 reales, según se desprende de los cuentas de propios y arbitrios del año 1791, una vez aclarado lo que se debía cargar en esta contabilidad. En total se gastaron 176.385 reales y 27 maravedís, de los que 166.800 se pidieron prestados a los efectos de las barcas del Ulla y Sarandón y lo restante se tomó de los fondos de propios ${ }^{60}$; como conse-

56 El 16 de febrero de 1789 los comisarios informan a la ciudad de haber sacado 100.000 reales de los depósitos de las barcas, y que al menos necesitarán unos 40.000 reales más (AMS, Consistorios de 1789, 1' semestre, fs. 119vto-120vto). Los actos se celebraron del 21 al 24 de febrero; la libranza de los 100.000 reales la aprobó la Junta de Propios y Arbitrios a finales de enero (AMS, Juntas de Propios y Arbitrios, 1787-1791, fs. 219 y vto). Un estudio sobre el valor y evolución de los arrendamientos de este derecho de circulación en el siglo XVIII, en GeLABERT GonzÁlez, J. E., «Dos indicadores de la coyuntura económica en la Galicia del siglo XVIII: los barcages de Ulla y Sarandón, 1740-1787», Compostellanum, 1-4 (1972), págs. 289-295.

57 AMS, Consistorios de 1790, $1^{\text {er }}$ semestre, fs. 222vto-223.

58 AMS, Consistorios de 1790, $2^{\circ}$ semestre, fs. 263 vto.

s9 AMS, Consistorios de 1791, $1^{\text {er }}$. semestre, f. 210 . Una advertencia similar recibió el municipio coruñés tras la proclamación de Carlos IV; aunque en esta ocasión se admitió el gasto de 63.400 reales en refrescos y saraos, el Consejo ordena que en adelante no vuelva a realizarse (MARtínez BARbeito, C., "Las reales proclamaciones...», pág. 63).

60 AMS, Junta de Propios y Arbitrios, 1792-1794, fs. 105 y vto. 
cuencia de este gasto, el saldo de propios de 1791 fue negativo, con un déficit de 94.055 reales, los que se debian a los fondos de barcas ${ }^{61}$.

Más drástica fue la medida adoptada dos años después a propósito de una cantidad librada por el tesorero de propios y arbitrios para ir a felicitar al arzobispo Malvar por el nombramiento de su sobrino Don Pedro Acuña como Secretario de Gracia y Justicia en 1792. Para la ocasión se aprobó una libranza de 3.000 reales, que después el tesorero incluyó entre los descargos correspondientes a ese año ${ }^{62}$. Al tratarse de un gasto realmente extraordinario, debía contar con la aprobación expresa del Consejo, por lo que el intendente lo rechazó cuando se le remitieron las cuentas correspondientes. El asunto aún coleaba en 1794, a juzgar por el informe que el síndico personero de Santiago, Don Ignacio Aguayo, presenta en mayo de ese año, y en el que señala claramente cuál era el procedimiento que debería haberse seguido y la solución propuesta, que no era otra que responsabilizar al tesorero de ese gasto ${ }^{63}$.

Las dificultades de financiación persisten años después, y seguramente más acentuadas por los sucesos bélicos y políticos; una muestra de ello se encuentra en la previsión de gasto y financiación que se hizo para la proclamación constitucional de 1812. Los comisarios de la ceremonia estimaron en unos 30.000 reales el gasto, fuerte pero justificado por tratarse de «un asunto nunca visto» ${ }^{64}$; puesto que el Ayuntamiento carecía de medios - los fondos de propios y arbitrios estaban muy mermados - se decidió emplear los fondos de cualquier otra partida municipal «con calidad de reintegro" 65 .

\section{COMENTARIO FINAL}

Se puede decir que en lo tocante a la cuestión económica de las celebraciones, la relación que pueda establecerse entre el estado financiero de las instituciones organizadoras y el gasto realizado es más bien débil. Es muy probable que en las épocas de escasez no se gastara excesivamente; fuera de esta situación, no parece acertado tratar de encontrar un paralelismo en la marcha de los indicadores económicos que

1bidem, fd. 109 .

62 Ibidem, fs. $132-133$ y 264 vto.

63 Ibidem, f. 384

${ }^{64}$ AMS, Consistorios de 1812, enero-julio, f. 360.

$65 \mathrm{lbidem}, \mathrm{f}$. 363vto. Algunas discusiones sobre el modo de financiar la celebración en fs. 364-365. 
pueden conocerse más fácilmente en el Antiguo Régimen y los gastos generados por las fiestas. Los casos mencionados en las páginas precedentes ponen en evidencia que cuando no hay recursos no por eso se suspenden las ceremonias y festejos; el interés político y social de estos actos parecen justificar sobradamente unos gastos que, como se ha visto, comprometen no sólo la liquidez económica de ese momento concreto, sino los ingresos próximos inmediatos.

Tal vez la novedad más destacable haya sido el intento de un mayor y mejor control de los gastos a partir del reinado de Carlos III, y un cierto interés por utilizar una parte de los fondos destinados a las celebraciones y ceremonias públicas a fines sociales, si bien el calificativo resulta un tanto pretencioso, pues se deja entrever claramente el interés propagandístico y de remozamiento de la imagen de la Corona. A finales de 1771, una real orden da cuenta de la voluntad de Carlos III de emplear una parte del dinero destinado a la celebración del nacimiento de un infante a dotar doncellas pobres y huérfanas ${ }^{66}$; en el caso de Santiago, se le autorizaba a emplear en este fin 8.000 reales ${ }^{67}$. Se une a la disposición anterior otra que establecía un indulto a determinados presos ${ }^{68}$. Desde 1771 en adelante, ambas medidas se pusieron en práctica en varias ocasiones; también en celebraciones de otra índole se encuentran disposiciones similares, si bien en este caso no como consecuencia de reales órdenes, sino de la iniciativa de los organizadores ${ }^{69}$.

66 La disposición del Consejo en AMS, Consistorios de 1771, septiembre-diciembre, fs. 125 126vto; el procedimiento para la distribución de las dotes en Ibidem, fs. 128-131.

67 Ibidem, f. 132.

s8 Ibidem, f. 163.

69 A finales de 1816 se celebró en Orense el nombramiento cardenalicio de su obispo D. Pedro Quintano y Quevedo; además de los consabidos fuegos artificiales, repiques de campanas, construcciones efímeras y ceremonias religiosas, el nombramiento se celebró con algunas limosnas y ayudas especiales: seis dotes para el colegio de expósitos y huérfanas de Orense, vestir seis niños de las escuelas de primeras letras, y zapatos y medias para los seises del coro (Fiestas y obsequios del IImo. Sr. Deán y Cabildo de la Santa Iglesia catedral de Orense a su dignisimo obispo, el eminentísimo señor D. Pedro Quevedo y Quintano, en celebridad de haber sido creado presbitero cardenal de la Santa Iglesia Romana. Madrid, Imprenta de M. Burgos, 1817, pág. 17) 